\title{
UNIDADES DE DISCURSO NOS PLANOS DE ENSINO DE GEOGRAFIA: ESTÁGIO, FORMAÇÃO DOCENTE E O JOGO DA CONTINUIDADE
}

\author{
DISCURSIVE UNITS IN GEOGRAPHY TEACHING \\ PLANS: INTERNSHIP, TEACHER EDUCATION AND \\ THE CONTINUITY GAME
}

\begin{abstract}
Amanda Regina Gonçalves*
RESUMO: A produção escrita de professores em formação inicial apresentada nos relatórios de estágios supervisionados aponta para os modos como os licenciandos lidam com o universo das linguagens na universidade contemporânea e quais saberes mobilizam para materializar as aulas na escola. A escrita dos Planos de Ensino nos estágios supervisionados de Licenciatura em Geografia de uma universidade pública está na centralidade deste texto e compõe o corpus analítico do trabalho. Os pressupostos teórico-metodológicos de investigação estão alicerçados na compreensão da "unidade do discurso", de Michel Foucault (2008), considerando, principalmente, as noções de "tradição, influência, evolução e mentalidade" no jogo discursivo dos Planos de Ensino. Como resultados, foram identificadas e postas em questão as formas discursivas dos planos, emergindo, então, um corpus de dados que se determina pela estrutura, ganhando existência um planejamento de aulas construído com regras de unidades de discurso que se repetem, presas num jogo de continuidades em seu sistema discursivo.
\end{abstract}

Palavras-chave: Formação docente; Ensino de Geografia; Planejamento de ensino; Unidades Discursivas

ABSTRACT: The written production of teachers in initial training presented in the supervised internship reports points to the ways in which undergraduate students deal with the universe of languages at the contemporary university and what knowledge they mobilize to materialize classes at school. The writing of the Teaching Plans in the supervised undergraduate courses in Geography of a public university is at the center of this text and makes up the analytical corpus of the work. The theoretical-methodological assumptions of investigation are based on the understanding of the "unity of discourse", by Michel Foucault (2008), considering, mainly, the notions of "tradition, influence, evolution and mentality" in the discursive game of the Teaching Plans. As a result, the discursive forms of the plans were identified and questioned, and then a corpus of data emerges that is determined by the structure, gaining existence a lesson plan built with

\footnotetext{
"Doutora em Geografia e Mestre em Educação e Licenciada em Geografia pela Universidade Estadual Paulista "Júlio de Mesquita Filho" (UNESP). Professora do Instituto de Geografia da Universidade Federal de Uberlândia (UFU). Contato: goncalves.amanda@gmail.com
} 
rules of repeated units of discourse, trapped in a game of continuities in your discursive system.

Keywords: Teacher education; Geography teaching; Teaching planning; Discursive units.

\section{INTRODUÇÃO}

Este texto apresenta um breve diagnóstico da relação de licenciandos com a produção de conhecimento mobilizada no planejamento de suas primeiras aulas de Geografia no espaço escolar, previstas nos estágios supervisionados obrigatórios.

A investigação parte de inquietudes surgidas em experiências provindas da atuação na formação docente de professores de Geografia no ensino superior público ao longo da última década.

As produções escritas de professores em formação inicial apresentadas nos relatórios de estágios supervisionados estão na centralidade deste texto, em especial, a formação discursiva dos estagiários referente ao planejamento das aulas e o próprio plano de ensino apresentado nos relatórios.

A análise proposta foi produzida a partir de pressupostos teóricometodológicos de investigação alicerçados na compreensão da "unidade do discurso", que Michel Foucault (2008) apresenta no livro "A arqueologia do saber", considerando, principalmente, as noções de "tradição, influência, evolução e mentalidade" no jogo discursivo dos Planos de Ensino.

Trata-se de uma pesquisa inserida no âmbito de um projeto de pesquisa mais amplo ${ }^{1}$ e se desenvolve na esteira das questões centrais do projeto, que são: a leitura e a escrita produzidas na universidade contemporânea - aqui, especificamente, na licenciatura em Geografia - se configuram como um recurso

\footnotetext{
${ }^{1}$ O projeto de pesquisa no qual este trabalho está inserido é intitulado "Leitura e escrita no Brasil, Honduras, Angola e Chile: formação na universidade contemporânea e (re)produção de conhecimento", aprovado pelo CNPq/Universal MCTIC/CNPQ ํㅡ 28/2018, Processo: 427044/2018-9, do qual faço parte a partir da participação em um dos grupos que compõe os pesquisadores do projeto, o Grupo de Estudos e Pesquisa em Análise do Discurso, Leitura e Escrita (GEPADLE), sediado na Universidade Federal do Triângulo Mineiro (UFTM), em Uberaba-MG.
} 
constitutivo de conhecimento e, consequentemente, do sujeito que a produz? Como lido, enquanto professora formadora dos futuros professores de Geografia, com os problemas de leituras e escrita apresentadas nessas produções?

O texto está organizado em quatro partes. Na primeira parte, após esta introdução, contextualiza-se brevemente o estágio obrigatório no contexto curricular dos Cursos de Licenciatura no Brasil. A segunda parte situa o percurso de construção dos planos de ensino analisados, no interior do estágio obrigatório do Curso de Licenciatura em Geografia, da Universidade Federal do Triângulo Mineiro (UFTM), em Uberaba-MG. A parte três apresenta as direções teóricometodológicas das análises, sobretudo os instrumentos utilizados para a pesquisa apoiados em Foucault (2008). Por fim, há uma sessão em que os discursos dos planos de ensino de Geografia dos estagiários são tomados para análise; seguido das considerações finais do trabalho.

\section{O ESTÁGIO SUPERVISIONADO NO CONTEXTO DA LICENCIATURA}

Ainda que restrito e, muitas vezes, isolado em relação aos demais componentes curriculares do Curso de Licenciatura, é indiscutível o impacto do estágio ao longo do percurso formativo do professor no ensino superior.

Há décadas a literatura acadêmica constata a importância, as dificuldades e alerta para a necessidade de mudanças no trabalho nos estágios obrigatórios dos Cursos de Licenciatura em Geografia no Brasil (PONTUSCHKA, 1991/1998, p. 101). Algumas dessas mudanças encontram amparo nas bases legais ${ }^{2}$ mais recentes do estágio, mas muito ainda falta para instituições de ensino superior e cursos construírem o estágio com base em uma visão mais integradora e colaborativa (tanto no âmbito interno dos cursos e instituição, quanto com a

\footnotetext{
${ }^{2}$ A lei federal de estágio $n^{\circ} 11.788 / 2008$, as resoluções do Conselho Nacional de Educação (CNE)/Conselho Pleno (CP) no 01/2002 e 02/2002 das Diretrizes Nacionais Curriculares (DCNs) para formação de professores da educação básica e, mais recentemente, da resolução CNE/CP no 2/2015, que define novas DCNs para a formação inicial em nível superior e para a formação continuada, a partir da qual muitas instituições ainda estão em processo de transição e adaptação curricular.
} 
educação básica), explicitarem com clareza e buscarem viabilizar seu projeto para a formação de professores.

A partir dos anos dois mil no Brasil estenderam-se estudos e publicações centradas nos saberes docentes (TARDIF, 2002), quando os estágios e práticas de ensino passam a ter presença maior como objeto e fonte das pesquisas, a exemplo dos resultados de uma pesquisa embasada em escritas narrativas de estagiários de quatro cursos de Licenciatura em Geografia de quatro universidades públicas da Região Sul do Brasil:

Compreendendo que os saberes da docência se constituem num processo de seleção, organização e sistematização do conhecimento, identificamos que o estágio supervisionado em Geografia oportuniza a mobilização de diferentes saberes profissionais, disciplinares, curriculares e experienciais, possibilitando aos estagiários a apropriação destes saberes de acordo com as demandas da prática pedagógica (MARTINS; TONINI, 2016, p. 104).

Além disso, destaca-se o Programa Institucional de Bolsa de Iniciação à Docência (PIBID) como um importante e inédito programa nacional de formação inicial de professores instituído em 2006. No entanto, conforme analisado por Selma Garrido Pimenta e Maria Socorro Lucena Lima (2019, p. 1), por mais que o Pibid se instale nos mesmos espaços institucionais por onde transita o estágio curricular supervisionado, eles "não se juntam em objetivos e atividades comuns para fortalecer uma política de formação docente no país que supere a lógica da formação fragmentada, individualista e competitiva", além de estar sofrendo redução de bolsas e risco de extinção. O mesmo pode ser aludido sobre o Programa Residência Pedagógica (PRP), outro programa ${ }^{3}$ que passou a conviver institucionalmente com os estágios desde 2018; este ainda acrescido de intensas críticas de estudiosos do campo da educação, por inserir-se em formatos pragmáticos e de precarização da docência e, uma vez vinculado ao estágio, submetê-lo à Base Nacional Comum Curricular (BNCC), ferindo a autonomia universitária (ANPED, 2018).

\footnotetext{
${ }^{3}$ Ambos os programas - PIBID e PRP - são financiados pela Coordenação de Aperfeiçoamento de Pessoal de Nível Superior (CAPES), vinculada ao Ministério da Educação do Brasil.
} 
Nesse contexto nacional envilecido a educação básica e a superior no Brasil têm sido conduzidas a profundas crises por meio de diversas medidas e políticas públicas nacionais, sobretudo a partir do ano de 2016, que promoveram alterações radicais na organização e no currículo do ensino fundamental e médio, apagando ou diluindo disciplinas do currículo, tais como a de Geografia, por meio da Reforma do Ensino Médio (Lei Federal no 13.415/2017) e da Base Nacional Comum Curricular - BNCC (BRASIL, 2018). Esses foram os antecedentes para a tramitação da Base Nacional Comum para Formação de Professores da Educação Básica (Resolução CNE/CP n 2/2019), que instrumentaliza processos de desprofissionalização da carreira docente, gera padronização curricular alinhada à BNCC, desconsidera a autonomia das universidades e sustenta-se em princípios e valores mercadológicos de educação. Em 2020, as Ciências Humanas foram duramente lesadas, quando critérios definidos pelo CNPq (MCTIC/Portaria 1.329/2020) excluem as ciências básicas, sociais e humanidades do fomento à pesquisa.

Este sistema de relações entre formação inicial e atuação profissional está descrito nos relatórios de estágio. Escritas, como as destacadas a seguir, revelam que este contexto impacta o processo de tornar-se professor dos licenciandos, sobretudo quando o contato com a realidade revela as problemáticas educacionais em que a escola e seus sujeitos se inserem, ainda que, muitas vezes sem materializar na escrita a consciência de conjunturas a que tais problemáticas estão relacionadas.

Cada vez que ganho mais experiência no contexto escolar, mais eu admiro a profissão de um professor. Não é um emprego fácil, não é bem remunerado e nem é valorizado pela sociedade. Não deve ser fácil mesmo, ter que trabalhar tanto e ainda ter que suportar tanta coisa, entre elas: agressão física, psicológica, cansaço e etc. (A7RE2) ${ }^{4}$.

A experiência da docência foi extraordinária para mim. Vivenciei situações de profunda alegria e também em alguns momentos de muita decepção (A4RE2, p. 43).

\footnotetext{
4 Para preservar as identidades dos(as) estagiários(as) são usados códigos para nomeá-los, por exemplo, A7RE2 é usado para designar o autor sete do Relatório do Estágio Curricular Supervisionado II do Curso de Licenciatura em Geografia da UFTM. Tal relatório compõe o banco de dados do projeto em que este trabalho está inserido, conforme apresentado anteriormente.
} 
Entre as principais particularidades das escritas de estágio está o fato delas poderem partir do princípio de serem textos "escritos no contexto", de serem enunciados de um sujeito, com seus saberes e poderes, que dá espaço à experiência na escola, como um acontecimento da sua vida, que foge da previsão pedagógica. Partindo de premissas de Foucault (2008, p. 11), é nesta relação geral entre as formulações que o texto do estágio "sofre efeito do contexto", um contexto que impele o estagiário a descrever a profissão de professor com negativas condicionantes do seu exercício: "não fácil", "não bem remunerado" e "nem valorizado pela sociedade", ainda que a admire.

Os enunciados postos em funcionamento nas escritas de estágio podem fugir daqueles em que os sujeitos autores não deixam rastros. Ao escrever que o professor tem que "suportar agressões física, psicológica e cansaço", ou escrever sobre sentimentos e emoções, como de "alegria" e "decepção", o estagiário contrapõe-se a uma escrita sem corpo. Trata-se de uma escrita que pode estar aberta a fugas daquela constituída apenas por formações de discursos que apelam para tradições (como temas de origem histórica no campo de conhecimento da educação ou do ensino de Geografia), ou ainda daquela escrita que se estabelece num feixe de relações das funções dos sujeitos, como a da posição do sujeito licenciando no lugar institucional do estágio que situa 0 relatório como parte dos requisitos para graduar-se e do leitor ser o professor avaliador desse relatório.

Isso demonstra como a escrita do estagiário tem necessitado de maior atenção nos cursos de licenciaturas. Sendo marcante o papel das narrativas, pois elas primam pela valorização das experiências e permitem dar organicidade ao planejamento das aulas, objeto da parte seguinte deste texto.

\section{PERCURSO DE CONSTRUÇÃO DOS PLANOS DE ENSINO NO ESTÁGIO}

Os Planos de Ensino analisados constam em relatórios de estágio supervisionado produzidos por professores em formação inicial na Licenciatura em Geografia, ofertada na Universidade Federal do Triângulo Mineiro (UFTM), Campus Uberaba-MG. Os relatórios selecionados resultam do segundo estágio 
cursado pelos licenciandos, após os mesmos terem concluído o primeiro estágio e também metade ou mais das disciplinas ofertadas pelo curso, sendo o primeiro estágio centrado no reconhecimento das dimensões político-pedagógicas e socioculturais da instituição escolar campo de estágio, onde terá continuidade o estágio seguinte.

A modalidade de relatório utilizada para avaliação formativa nestes estágios é o "portifólio", entendendo que sua construção pode conter evidências das experiências do trabalho realizado e do desenvolvimento acadêmico e profissional do seu autor. A orientação é para que o portifólio do período de regência seja composto, com algumas poucas variações entre as turmas de estagiários, pelos seguintes elementos textuais mínimos: capa, sumário; trabalhos relacionados aos estudos teórico-metodológicos realizados ao longo do estágio; texto narrativo-reflexivo sobre aulas observadas, turmas de alunos e planejamentos de ensino do(a) professor(a) da turma; planos de ensino; texto narrativo-reflexivo das aulas desenvolvidas; formulário de acompanhamento das atividades de estágio e parecer do supervisor do estágio.

O planejamento do ensino é objeto de estudo teórico-metodológico realizado em aulas presenciais de orientação ao estágio ${ }^{5}$. Em seguida, propõese e debate-se o conteúdo mínimo para os planos de ensino (dados da unidade escolar, supervisor, estagiário, disciplina, turma, data, hora/aula, tema, conteúdos, objetivos, sequência das atividades, questão problematizadora, tarefas e procedimentos e instrumentos mediadores). Após isso, os planos são elaborados individualmente pelos estagiários, apresentados e discutidos junto à turma e orientadora, bem como junto ao(à) supervisor(a) de estágio (professor(a) da disciplina de Geografia da turma de alunos na qual o estagiário desenvolverá as aulas planejadas). O texto-discursivo resultante desse processo é apresentado no portifólio de estágio, sendo ele o corpus selecionado para esta investigação.

Nos relatórios de estágio, quando o estagiário escreve sobre 0 planejamento da aula do professor observado, ele se posiciona diante dos

\footnotetext{
${ }^{5}$ Alguns dos trabalhos que fazem parte dos estudos nesse momento do estágio são: Núñez (2009); Gonçalves (2018); Libâneo e Freitas (2009); Larrosa (2002) e Nascimento e Macedo (2015).
} 
problemas encontrados na sala de aula e da atividade de planejamento do professor, a exemplo dos trechos a seguir:

\begin{abstract}
Algo que me chamou a atenção nas escolhas profissionais do professor foi a questão por optar em não realizar planejamentos de aula regularmente. Ele segue os parâmetros do livro didático. Os encaminhamentos da aula ocorreram de forma regular (p. 29). (...) Conclui-se que o planejamento é um instrumento crucial à prática docente e inerente a ela (A8RE2, p. 46).
\end{abstract}

As aulas [observadas] foram todas pragmáticas, embasadas na pedagogia diretiva e sem momento para fala dos alunos. Construídas através de slides, com textos a serem copiados que já estavam contidos nos livros didáticos. (A9RE2, p. 27, inserção nossa).

$\mathrm{Na}$ maioria das escritas, os estagiários distanciam-se da imagem do professor da escola com palavras negativas em relação às ações observadas e projetam práticas ideais sobre o planejamento na docência, o bom professor e a imagem de si mesmos, como por exemplo, quando o estagiário escreve que o professor "opta por não realizar planejamentos de aula regularmente" e conclui que a atividade de planejamento "é um instrumento crucial para a prática docente e inerente a ela". Uma formação discursiva que se dá no plano do dever ser e não do devir do planejamento e da aula. Enunciados classificatórios e críticos às aulas do professor, formulados sem articulação com as leituras e estudos que contextualizam as contingências socioculturais e políticas do trabalho do professor na escola pública e na educação brasileira.

Diferente de como aborda a prática do outro, o estagiário, quando escreve sobre sua prática de ensino no estágio, geralmente, descreve a imagem ideal de professor no exercício de suas funções na educação dos alunos. Por outro lado, os relatórios de estágio também revelam uma regularidade quanto à insatisfação destes em relação ao trabalho de planejamento das aulas. Observamos estas formações discursivas nos dois fragmentos a seguir:

As [minhas] aulas em sua essência foram expositivas e dialogadas. A metodologia usada no estágio foi a mais objetiva, coerente e exequível possível, visando o cumprimento dos objetivos, contidos nos planos de aula, procurando otimizar o processo de ensino-aprendizagem (A12RE2, p. 22, inserção nossa)

O estágio é uma etapa de grandes desafios, pois nos coloca de frente com uma sala de aula pela primeira vez, num misto de ansiedade e perspectivas, de uma aula que fora planejada com tanto esmero, e que 
pode estar fadada ao fracasso, diante de turmas como as do Ensino Fundamental II que estão cheias de energia, e da falta de experiência do estagiário. (A1RE2)

São formulações discursivas como estas, materializadas nas escritas dos estagiários, que compõem a fonte de informações para entender o planejamento da prática de ensino e as discursividades dos planos de ensino escritos pelos estagiários. Um plano que guarda uma relação não determinística entre o sistema discursivo e os contextos de realização da ação. Planejamentos que são compreendidos em um processo mais amplo do âmbito pedagógico, em que:

\begin{abstract}
a própria atividade de construção de uma sequência didática inserida em um estágio supervisionado é também uma prática e pesquisa em ensino, sendo assim mediação da formação docente, na dimensão prática e teórica e, no curso de licenciatura, na dimensão ensinoextensão-pesquisa (SOUZA; JULIASZ, 2020, p. 159).
\end{abstract}

Em busca de direções teórico-metodológicas para analisar a materialidade destes planos de ensino que se desenvolve o item a seguir.

Antes, ainda é preciso reconhecer que, como professora orientadora dos estagiários-futuros professores de Geografia, não estou segura do uso das distinções discursivas nos meus próprios planos de ensino. Entendendo-os como "discursos estudados", "são sempre, eles próprios categorias reflexivas, regras normativas, tipos institucionalizados" (FOUCAULT, 2008, p. 25), os quais merecem ser analisados ao lado dos outros, porque com eles mantém relações complexas.

\title{
DIREÇÕES TEÓRICO-METODOLÓGICAS DAS ANÁLISES
}

Para conduzir as análises neste texto, nos apoiamos na compreensão da "unidade do discurso", que Michel Foucault (2008) apresenta no livro "A arqueologia do saber", tomando como instrumento para a pesquisa as noções de tradição, influência, evolução e mentalidade no jogo discursivo dos Planos de Ensino. 
Assim como Foucault aponta na introdução desse livro sobre a atenção dos historiadores ${ }^{6}$ ao trabalho ter sido historicamente a de revelar equilíbrios estáveis, as regulações e os fenômenos tendenciais utilizando modelos, análises quantitativas e constantes sociológicas como instrumentos, também partimos da compreensão de que por longos períodos as pesquisas educacionais também buscaram esses caminhos, que agora foram substituídas por um jogo de interrupções e multiplicação dos níveis de análise, cada um com suas rupturas específicas. Aqui, procuraremos detectar a incidência do jogo de continuidades nos planos de ensino, mas para conhecer seus limites e, para isso, a movimentação para o levantamento dos dados nos relatórios de estágio partiu de questões como: que tipos de planos de ensino são escritos? Que sistema de relações pode ser descrito entre os tipos de planos?

O problema que se coloca às análises não é mais saber como estabelecer caminhos para a escrita de um plano de ensino (como foi o objeto do texto de Micotti, 1994 e de Fusari, 1990) ou como construir um modelo único de plano de ensino, mas sim conhecer os limites do plano de ensino e as transformações que o fundamentam hoje. Portanto, se, como professores, identificamos rapidamente os itens básicos que devem conter tradicionalmente um plano de ensino (conteúdo, objetivo, metodologia, recurso, avaliação) buscam-se as perturbações dessa continuidade.

O movimento é o de, como professora formadora de professores, não me servir da materialidade documental dos relatórios de estágio para edificar formas de permanências das minhas aulas e orientações ao estagiário, ou seja, não fazer do ato de planejar uma aula um objeto da formação do professor Geografia que "memoriza" os monumentos do passado e transforma os documentos, no caso os relatórios de estágio e os planos de ensino, em monumentos,

\footnotetext{
${ }^{6}$ Entendem-se, nesse trabalho, historiadores no amplo sentido dado por Foucault (2008), daquele que atua no campo das "disciplinas chamadas história das ideias, das ciências, da filosofia, do pensamento e da literatura (a especificidade de cada uma pode ser negligenciada por um instante) (p. 4), "tanto quanto nas que dizem respeito à economia e às sociedades" (p. 15), entende-se incluir, portanto os campos da Educação e do Ensino de Geografia. Sendo a historiografia, da qual o autor fala, ser mais método do que disciplina, para uma ontologia do presente, ou seja, para as análises que constituem a arqueologia das ciências humanas, na qual essa pesquisa busca instrumentos para análise das discursividades na formação de professores de Geografia na atualidade, intencionando a possibilidade de transformação dos processos históricos de subjetivação no campo da Geografia Escolar.
} 
reestabelecendo discursos históricos do campo educacional, da formação de professor e do ensino de Geografia.

A formação de professores de Geografia e, por conseguinte, o estágio, como disciplina dos monumentos pode se voltar para a produção de planos de ensino sem contexto, que só tomam sentido pelo reestabelecimento de discursos educacionais e geográficos fixados no tempo, o que dá status a tal massa documental, portanto a tais discursos, dos quais a disciplina não se separa. É neste sentido que podemos apreender de Foucault (2008, p. 8) o movimento de voltar-se para a "arqueologia - para a descrição intrínseca do monumento", no caso, dos Planos de Ensino.

\section{UNIDADES DO DISCURSO E O JOGO DAS CONTINUIDADES NO PLANEJAMENTO DAS AULAS}

Ao iniciar uma arqueologia dos Planos de Ensino dos estagiários, encontramos estabelecimentos metodológicos que antecedem há muito sua elaboração por esses estagiários, mas que acabam por caracterizar a constituição de um corpus coerente e homogêneo de documentos. Esta situação pode ser percebia na maioria dos planos de ensino apresentados nos relatórios de Estágio. Conforme apresentado em tópico anterior sobre o percurso de construção dos planos de ensino no estágio, eles partem de uma estrutura mínima, expressa em letra itálica nos trechos citados, apresentada na disciplina. A seguir, estão transcritos dois planos de ensino com o sistema discursivo predominante na sua escrita:

PLANO DE ENSINO - Escola Pública X - Disciplina: Geografia - Turma de alunos: $7^{\circ}$ ano do Ensino Fundamental - Duração: 1h/a

- Conteúdos: População e Trabalho: mulheres, crianças e idosos: População e os setores de produção; Mulheres: mercado de trabalho; Desigualdade salarial e escolaridade; Trabalho Infantil; Pirâmides etárias; Envelhecimento da população.

- Problematização do tema de estudo: Relacionando os dados de Uberaba e Brasil, porque o setor primário emprega menos a população? Qual setor (e as atividades econômicas) que mais gera emprego para a população de Uberaba? Você saberia identificar uma criança em situação de trabalho infantil? Em quais Estados a desigualdade salarial entre homens e mulheres é maior?

- Objetivos da aprendizagem dos alunos: Entender quais são os setores produtivos e suas funções; Compreender e identificar a distribuição da população nos setores produtivos; compreender e 
analisar a entrada da mulher no mercado de trabalho; compreender e comparar a desigualdade salarial entre homens e mulheres; Identificar as questões que envolvam o trabalho infantil; interpretar gráficos de pirâmides etárias; Relacionar os dados dos gráficos com 0 envelhecimento da população.

- Mapa conceitual (...)

- Desenvolvimento metodológico: 2h/a: Sequência das atividades: Questão problematizadora e reconhecimento dos conhecimentos prévios dos alunos (10 a $15 \mathrm{~min}$ ); Explicação sobre o conteúdo dos setores produtivos (15min); Explicação sobre a mulher e o mercado de trabalho e questão problematizadora (para responder depois individualmente na tarefa) (20 min); Explicação sobe pirâmides etárias e o envelhecimento da população (20 min.); Esclarecimento de duvidas (10 min.)

- Instrumentos mediadores e materiais: Slides, texto informativo, dados quantitativos, gráficos, tabelas e mapas.

IBGE. Acesso em maio/2017: https://cidades.ibge.gov.br/

REDAÇÃO. 17 de março de 2016

http://www.cartaeducacao.com.br/reportagens/brasil-tem-3-milhoes-

de-trabalhadores-infantis/

Edição: Lidia Neves. Andreia Verdélio - Repórter da Agência Brasil http://agenciabrasil.ebc.com.br/geral/noticia/2017-03/mulheres-

trabalham-75-horas-mais-que-homens-devido-dupla-jornada

ADAS, Melhem; ADAS, Sergio. Expedições geográficas. São Paulo: Moderna, 2011. (A1RE2, p. 13-15)

PLANO DE ENSINO - Escola Pública Y - Disciplina: Geografia - Turma de alunos: $6^{\circ}$ ano do Ensino Fundamental

- Conteúdo: (4h/a) Revisão: O Universo e a Terra; Os movimentos da Terra; A insolação e a amplitude térmica; A circulação geral da atmosfera

- Objetivos da aprendizagem dos estudantes: Compreender como o eixo de inclinação da Terra influencia na temperatura; Compreender o funcionamento da dinâmica climática; Localizar as zonas térmicas; Compreender as relações e impactos da incidência da luz solar na Terra.

- Desenvolvimento metodológico: (2/a):

- Conteúdo: Os movimentos da Terra e A insolação e a amplitude térmica

Sequência das atividades: Em um primeiro momento, serão feitas questões para serem respondidas oralmente no sentido de identificar o conhecimento dos estudantes a respeito da temática "os movimentos da Terra, insolação e amplitude térmica". A partir disso, serão resgatados conceitos da Terra, como: 1 . Os movimentos de rotação e translação; 2. O eixo de inclinação da Terra; 3. Zonas Climáticas; 4. Dispersão da radiação solar sobre a superfície terrestre.

Após isso, já no segundo horário, trataremos a respeito das descobertas espaciais feitas pelo homem e a presença de satélites na órbita terrestre.

- Questões problematizadoras sobre a temática: Por quê temos diferentes estações no decorrer do ano? Caso o eixo terrestre não apresentasse uma inclinação de aproximadamente $23^{\circ}$, ainda seria possível observar uma maior amplitude térmica anual nas zonas temperadas? - 20 min

- Explicações sobre os movimentos da Terra - 15 min

- Explicações sobre insolação solar sobre a superfície terrestre e zonas climáticas - 30 min 
- Explicações sobre a presença de satélites na superfície terrestre e descobertas espaciais - 20 min

- Realização de exercícios do livro didático (RIBEIRO, Wagner C. Por Dentro da Geografia, 2015, p.54)

- Instrumentos mediadores e materiais: Livro didático de geografia, globo terrestre (A3RE2, p. 6-8).

Estes planos emergem como conjuntos de unidades do discurso que a história propõe sobre o planejamento de ensino pelos estagiários, sendo estes os conjuntos com que tenho me deparado ao longo dos anos como orientadora de estágio. Conforme Foucault (2008, p. 28), tais unidades revelam "formas prévias de continuidades e sínteses". Por exemplo, a escrita dos "conteúdos" de ambos os planos são repetições de subtítulos que compõem o sumário de livros didáticos de Geografia para os referidos anos escolares. Isso fica evidente ao observar o corpo de enunciado do "Sumário" do livro didático citado no plano de ensino: "População e Trabalho: mulheres, crianças e idosos: A população segundo os setores de produção; Mulheres e desigualdade no mercado de trabalho; O trabalho infantil no Brasil e A pirâmide etária do Brasil" (ADAS; ADAS, 2018, p. 8) - no plano de ensino em análise vê-se uma repetição, quase idêntica, desse corpo enunciativo.

Na escrita dos "objetivos", as regras são de repetição e continuidade das unidades de discurso dos "conteúdos" - portanto, do "Sumário" do livro didático - mas antecedidos por ações verbais previstas, desde 1956, na taxonomia de Bloom $^{7}$ para a elaboração de objetivos educacionais, como: conhecer, reconhecer, identificar, interpretar, relacionar e localizar.

Acrescenta-se o fato deste "Sumário" constar em uma edição do livro publicada sete anos após a citada pela estagiária (a terceira edição), ou seja, regularidade de repetição em um livro didático que, contíguo ao sistema de citações em planos de ensino, funciona como operador de síntese no jogo discursivo do planejamento de ensino. As noções de tradição, influência,

\footnotetext{
7 O livro "Taxonomy of educational objectives", de um grupo de pesquisadores norte americanos liderados por B. S. Bloom, de 1956, ganha notoriedade no meio educacional e marca certa unidade e homogeneidade na construção dos planejamentos de ensino, sobretudo, na escrita dos objetivos educacionais. Segundo Ferraz e Belhot (2010, p. 423), estudiosos de Bloom, "a taxonomia trouxe a possibilidade de padronização da linguagem no meio acadêmico e, com isso, também novas discussões ao redor dos assuntos relacionados à definição de objetivos instrucionais" (2010, p. 423, grifo nosso).
} 
evolução e mentalidade, a que se refere Foucault (2008, p. 23), se impõem como parte do jogo de noções desta continuidade das unidades de discurso dos Planos de Ensino. A seguir analisamos os planos a partir de cada uma dessas quatro noções.

A "tradição" se impõe quando evidenciamos uma importância temporal singular do conjunto de conteúdos sucessivos e quase idênticos na coleção de livros didático citada no plano pela estagiária. $O$ autor Melhem Adas escreve livros didáticos de Geografia desde 1976, sendo obras de "grande repercussão no cenário nacional” (ALMEIDA, 2018, p. 138). Essa tradição parece autorizar a redução do que seria começar um plano de conteúdos de ensino de Geografia para as diferenças características daquela turma de alunos e daquela escola ao retrocesso à origem dos enunciados em uma obra didática tradicional.

A "influência", segunda noção também aparece como uma legitimidade de transmissão e comunicação da obra que autoriza tal redução. Em 2017, ano em que o Plano de Ensino foi escrito, a coleção do livro didático citado ocupou o primeiro lugar no ranking das coleções adquiridas no Programa Nacional do Livro Didático de 2017 (PNLD/2017) e foram adquiridos 3.381 .582 exemplares pelo Ministério da Educação (MEC) (ALMEIDA, 2018, p. 19), portanto uma propagação colossal tanto no tempo (com livros didáticos de mesma autoria por mais de quarenta anos), como no espaço (com mais de três milhões de livros de uma só edição distribuídos em todo território brasileiro).

As noções de "desenvolvimento e evolução" são aquelas que, para Foucault (2008, p. 24),

\footnotetext{
permitem reagrupar uma sucessão de acontecimentos dispersos; relacioná-los a um único princípio organizador; submetê-los ao poder exemplar da vida (com seus jogos de adaptação, sua capacidade de inovação, a incessante correlação de seus diferentes elementos, seus sistemas de assimilação e de trocas).
}

As atividades, tarefas e procedimentos são elementos procedimentais, ainda que também teóricos, de uma aula, cujas escritas nos planos de ensino variam um pouco mais do que as dos conteúdos e objetivos, talvez pelos intensos discursos de "adaptação" e "inovação" na educação recaírem sobre os aspectos metodológicos da aula. 
No entanto, na escrita da "sequência de atividades" dos planos em análise, predomina a ação de "explicação sobre os conteúdos". Dos cem minutos totais de ambas as aulas planejadas, cinquenta e cinco minutos da aula de A1RE2 e sessenta e cinco minutos da aula de A3RE2 estão previstos para os alunos ouvirem "explicações" sobre os conteúdos pelo professor/estagiário. O método expositivo é uma das formas de organizar a atividade docente mais presente nos planos de ensino. Ele aparece de forma remissiva nas publicações de teóricos da educação, por exemplo: "sua característica essencial consiste na comunicação verbal por parte do professor em forma de narração ou demonstração" (STOCKER, 1973 apud GONÇALVES, 1984, p. 119) ou "o método expositivo, nucleado na exposição oral, estruturada, de uma temática de ensino (...) desenvolve-se, portanto, observando as motivações (...) e os elementos necessários à compreensão e à fixação de conceitos, premissas e processos" (RANGEL, 2008, p. 42).

Assim, o método expositivo de ensino persiste nos planejamentos de ensino e parece ser utilizado como um princípio organizador da aula, uma das características que Foucault (2008) atribui à noção de desenvolvimento e evolução das continuidades.

O livro didático referenciado nos conteúdos e, consequentemente, nos objetivos e atividades do plano de ensino estabelece-se com uma função precisa de desenvolvimento e evolução no tema da continuidade.

O autor do livro didático, para se manter no mercado editorial por mais de quarenta anos e na mesma editora, precisou adaptar sua obra a diferentes mudanças que foram surgindo ao longo do tempo, reagrupando uma sucessão de acontecimentos dispersos, como mudanças: surgidas de metodologias inovadoras e de enfoques da disciplina nos livros didáticos de Geografia no Brasil; instigadas por debates da própria disciplina, como inicialmente os da Geografia Crítica (abordagem teórico-metodológica da qual o autor aponta inicialmente partir em suas primeiras obras didáticas) e os da Geografia Humanista (abordagem teórico-metodológica que as obras passam a dialogar, sobretudo após a ascensão dos Parâmetros Curriculares Nacionais) e renovação da didática escolar (ora explorando mais textos ora mais mapas nos 
exercícios ao longo das edições); na materialidade (com livros também em formatos de multimídia) e visualidade (como infográficos) das formações discursivas da obra e, principalmente, nas legislações educacionais e nos critérios de avaliação do PNLD (a exemplo da Lei no 11.645/2008). "Os manuais escolares, publicados após a implantação dessa política pública para a educação básica, apresentam mudanças qualitativas, no que se referem ao padrão gráfico, aos conteúdos e à forma de atividades de sala de aula" (ALMEIDA, 2018, p. 85).

Concorrer ao PNLD significa submeter a obra ao "poder exemplar da vida" das muitas gerações de adolescentes e jovens estudantes, porque, conforme os planos de ensino atestam, materializam-se em poder exemplar da vida da disciplina Geografia nas escolas de todo território brasileiro, por isso o jogo de mudanças, resistências e permanências. Jogo esse que se dá numa incessante correlação dos diferentes elementos do livro e seus sistemas de assimilação e de trocas que lhe garantiram manter-se na editora, no mercado de livros didáticos brasileiros, no Guia de Livros Didáticos do PNLD e nas escolas via escolha dos professores de Geografia e materialização nos seus planos de ensino.

Um intenso fato, ou acontecimento, que mantém as relações complexas da unidade de discurso da obra é que a coleção "Expedições Geográficas" é financiada e vendida pela Editora Moderna, uma empresa brasileira, que publica livros didáticos e outros desde 1968, que se tornou uma das líderes desse mercado brasileiro de livros educativos, sendo a quarta maior em venda de exemplares e em lucratividade, de acordo com pesquisa da Revista Nova Escola (2017 apud ALMEIDA, 2018, p. 137). Em 2001, a editora Moderna passou a integrar o Grupo Santillana, atuante no mercado editorial de materiais didáticos de vinte e sete países (ALMEIDA, 2018, p. 137), portanto cujas redes de regras normativas e tipos institucionalizados em que o livro se insere, facilmente perdem sua evidência.

Dessa forma, a descrição do plano analisado como um nó nessa rede discursiva leva a reconhecer que os Planos de Ensino não são um lugar tranquilo dos discursos escolares. Ao contrário, demonstra como as margens de um plano 
de ensino jamais são nítidas e como o plano está preso em um sistema de remissões a outra obra didática atravessada pelas noções de continuidade das unidades de discurso nos planejamentos de ensino da disciplina de Geografia.

A última noção que interliga os discursos é a de "mentalidade" ou de "espírito", sendo ela, segundo Foucault (2008, p. 24), a que permite estabelecer entre os fenômenos "uma comunidade de sentido, ligações simbólicas, um jogo de semelhança e de espelho - ou que fazem surgir, como princípio de unidade ou de explicação, a soberania de uma consciência coletiva".

Entre a maioria dos planos de ensino dos estagiários percebe-se um jogo de semelhança e espelho, tal como pode claramente ser visto entre os dois planos de ensino em análise. Desde as unidades de discursos em cada um dos itens do plano, assim como a organização metodológica e temporal da aula, sobretudo quanto às propostas de tarefas e procedimentos, e a seleção dos instrumentos mediadores, que se constituem como ligações simbólicas entre os Planos e que caracterizam uma consciência coletiva do que é um plano de ensino e, portanto, do ato de planejamento de aula pelos estagiários.

Recentemente, sobretudo a partir do ano de 2019, observa-se o aparecimento de uma ligação simbólica intensa que alimenta um jogo de semelhança e espelho dos Planos de Ensino, sendo ela o aparecimento, ora na escrita dos "conteúdos" ora na escrita dos "objetivos" dos planos, de apenas um código ou ele seguido de seu inexorável significado, como por exemplo:

Escola Pública - Disciplina: Geografia - Turma de alunos: $6^{\circ}$ ano do Ensino Fundamental

- Conteúdos: EF06GE06. (A10RE2, p. 3)

Escola Pública - Disciplina: Geografia - Turma de alunos: $8^{\circ}$ ano do Ensino Fundamental

- Conteúdos: (EF08GE23) Identificar paisagens da América Latina e associá-las, por meio da cartografia, aos diferentes povos da região, com base em aspectos da geomorfologia, da biogeografia e da climatologia (A10RE2, p. 13).

Tais códigos referem-se ao código alfanumérico estabelecido no documento curricular federal "de caráter normativo" homologado em dezembro de 2017, que diz com isso "atingir" "o objetivo de uma Base para toda a Educação 
Básica brasileira" (BRASIL, 2018, p. 5). Conforme normatiza a Base Nacional Comum Curricular:

\begin{abstract}
Nos quadros que apresentam as unidades temáticas, os objetos de conhecimento e as habilidades definidas para cada ano (ou bloco de anos), cada habilidade é identificada por um código alfanumérico cuja composição é a seguinte: EF67EF01. (...) Segundo esse critério, o código EF67EF01, por exemplo, refere-se à primeira habilidade proposta em Educação Física no bloco relativo ao $6^{\circ}$ e $7^{\circ}$ anos (BRASIL, 2018, p. 30).
\end{abstract}

A forte função de operador de síntese desse código no exercício da criação de unidades imediatas e universais de discursos nos planos de ensino de Geografia fica evidente ao identificarmos em diversos planos de ensino, escritos por diferentes sujeitos-estagiários para diferentes escolas e turmas de alunos, uma regra de aparecimento de um documento curricular nacional. Basta comparar o escrito pelo(a) estagiário(a) A10RE2 com o enunciado a seguir:

GEOGRAFIA - $8^{\circ}$ ANO (...) HABILIDADES: (EF08GE23) Id entificar paisagens da América Latina e associá-las, por meio da cartografia, aos diferentes povos da região, com base em aspectos da geomorfologia, da biogeografia e da climatologia (BRASIL, 2018, p. 391).

Para Foucault (2008, p. 24), "é preciso também que nos inquietemos diante de certos recortes ou agrupamentos que já nos são familiares". Neste sentido, depara-se com um documento curricular que tem sido amplamente questionado em todo o país e observa-se que a BNCC age como uma operação de síntese não só de ordem técnica-educacional, mas também política, econômica e social.

Dentre os muitos manifestos de professores e entidades educacionais brasileiras contrários à BNCC, aponta-se que esse documento representa um retrocesso à educação brasileira, como demonstra a "Carta de João Pessoa XIX Encontro Nacional de Geógrafos", de 07 de julho de 2018 (AGB, 2018, grifo nosso):

não aceitamos a BNCC, (...) pela sua estruturação com foco na aprendizagem sem a consideração do papel do professor no processo de produção do conhecimento, abrindo um flanco para a inserção das apostilas, materiais didáticos e das tecnologias produzidas pelo oligopólio educacional presente hoje no país; pela consolidação da Pedagogia das Competências, que funda programaticamente pela 
formação flexível e pragmática em tempos de precarização do trabalho e apropriação da subjetividade da classe trabalhadora; pela falácia discursiva de que uma padronização curricular promoverá as mesmas condições de aprendizagem para sujeitos de realidades sociais, culturais e territorialmente distintas; e pelo descarte de conceitos e temas relevantes para a construção do pensamento social crítico.

Assim, aquelas unidades discursivas dos planos de ensino demonstraram regras de aparecimento dos discursos que fazem surgir uma soberania de uma consciência coletiva.

Somando-se ao que foi analisado, é preciso registar que quando o Plano de Ensino dos estagiários destina-se a aulas em escolas particulares, muitas vezes, os aspectos das quatro noções que constituem jogos de continuidade nos discursos dos planos de ensino são exponencialmente agravados, por dois fatores principais: a escrita dos elementos do plano baseia-se prioritariamente em sistemas apostilados de ensino e as tarefas em testes competitivos preparatórios para exames propedêuticos. Dessa forma, a escrita tipificada e a reprodução enunciativa dos títulos e números de módulos, capítulos, frentes e unidades dos materiais didáticos apostilados predominam nos itens do plano de ensino, assim como os exercícios previstos nas apostilas oriundos de vestibulares e do Exame Nacional do Ensino Médio de anos anteriores estão entre as tarefas mais propostas nos planos.

Agravados ainda porque tais materiais não passam pela avaliação do MEC e também porque o grau de padronização e de determinação dos sistemas de ensino apostilados sobre a construção da aula é mais intenso.

Por fim, sobre a análise feita, almejou-se por em questão as sínteses e agrupamentos que aparecem nos planos de ensino dos estágios de Ensino de Geografia, entendendo, conforme Foucault (2008, p. 24), que:

\footnotetext{
É preciso por em questão, novamente, essas sínteses acabadas, esses agrupamentos que, na maioria das vezes, são aceitos antes de qualquer exame, esses laços cuja validade é reconhecida desde o início; é preciso desalojar essas formas e essas forças obscuras pelas quais se tem o hábito de interligar os discursos dos homens; é preciso expulsá-las da sombra onde reinam.
}

Ao tirar da sombra esses agrupamentos discursivos, pode-se fazer emergir a maneira como a escrita do planejamento das aulas tem sido produzida 
nos estágios de licenciatura em Geografia e apontar para os modos de o sujeito contemporâneo se inserir nos universos de linguagens, uma busca do fortalecimento nestas produções de um sujeito capaz de explicitar as marcas de seu pensamento e as marcas de produção de conhecimento sobre 0 planejamento de aulas de Geografia.

\section{CONSIDERAÇÕES FINAIS}

A partir dos pressupostos da unidade de discurso, as pistas encontradas nos planos de ensino demonstraram as noções em jogo no seu sistema discursivo, que lhe impõem formas prévias de continuidade, as quais, se vistas de acordo com o jogo das continuidades analisadas por Foucault (2008, p. 28), o constitui em "um discurso sem corpo", que "mina o que é dito, que condena o discurso a ser busca e repetição de uma origem que escapa a toda determinação histórica".

A escrita dos professores em formação inicial apresentada nos relatórios finais do estágio, referente ao planejamento de suas primeiras regências, apresenta, em grande parte, regras de unidades de discurso e formas de continuidade presas em um jogo de noções de tradição, tradição, influência, evolução e mentalidade, conforme instrumentos de análise utilizados na arqueologia do saber por Foucault (2008).

Em parte, o corpus de dados analisados se determina pela estrutura, ganhando existência uma formação discursiva que se repete na maioria dos planos de ensino apresentados nos relatórios de estágio.

Foi iniciado aqui um trabalho, na esteira da obra "Arqueologia do Saber" de Foucault (2008, p. 29), de arrancar as unidades discursivas dos planos de ensino de sua quase-evidência, de liberar os problemas que colocam, de "reconhecer que não são o lugar tranquilo a partir do qual outras questões põem ser levantadas". Não se trata de recusar as escritas dos planos de ensino, mas de: 
cujas regras devem ser reconhecidas e cujas justificativas devem ser controladas; definir em que condições e em vista de que análises algumas são legítimas; indicar as que, de qualquer forma, não podem mais ser admitidas (FOUCAULT, 2008, p. 28).

Ao problematizar ou por em suspenso as sínteses e formas prévias de continuidade nos planos de ensino dos estagiários do Curso de Licenciatura em Geografia, outros conjuntos de enunciados encontram-se liberados para aparecer no planejamento das aulas de Geografia. Aos desfazer os planos, sabemos se podemos recompô-lo legitimamente e se podemos fazer 0 planejamento das aulas de Geografia à escola e aos alunos a que se destinam.

\section{REFERÊNCIAS}

ADAS, Melhem; ADAS, Sérgio. Expedições Geográficas: $7^{\circ}$ ano Componente Curricular Geografia. 3. ed.. São Paulo: Moderna, 2018.

ALMEIDA, Daniela Gomes de. Imagens, textos, ícones: análise dos arranjos visuais de livros didáticos de Geografia. Dissertação (Mestrado em Educação). Uberlândia-MG: Universidade Federal de Uberlândia (UFU), 2018. Disponível em: http://dx.doi.org/10.14393/ufu.di.2018.578. Acesso em 20 de julho de 2020.

Associação Nacional de Pós-Graduação e Pesquisa em Educação - ANPED. Entidades se posicionam contrárias à padronização e controle impostos pelo Programa de Residência Pedagógica! Não à BNCC! 2018. Disponível em:

http://www.anped.org.br/sites/default/files/images/manifesto programa residen cia pedagogica.pdf. Acesso em 15 de maio de 2020.

Associação Nacional dos Geógrafos Brasileiros - AGB. Carta de João Pessoa - XIX Encontro Nacional de Geógrafos, 07 de julho de 2018: Pela revogação da Lei da Reforma do Ensino Médio 13.415-2017. João Pessoa-PB: AGB/Diretoria Executiva Nacional, 2018. Disponível em: https://www.agb.org.br/wp-content/uploads/2019/04/MO\%C3\%87\%C3\%830-

GT-Ensino-BNCC.pdf. Acesso em 10 de maio de 2020.

BRASIL. Ministério da Educação. Base Nacional Comum Curricular: Educação é a Base. Brasília: MEC/CONSED/UNDIME, 2018.

FERRAZ, Ana Paula do Carmo M.; BELHOT, Renato Vairo. Taxonomia de Bloom: revisão teórica e apresentação das adequações do instrumento para definição de objetivos instrucionais. Gestão \& Produção, São Carlos, v. 17, n. 2, p. 421-431, 2010. Disponível em: 
https://doi.org/10.1590/S0104-530X2010000200015. Acesso em: 10 out. 2020.

FOUCAULT, Michel. A arqueologia do saber. 7 ed.. Rio de Janeiro: Forense Universitária, 2008.

FUSARI, José Cerchi. Planejamento do trabalho pedagógico: algumas indagações e tentativas de respostas. Idéias, São Paulo, n. 8, p. 44-53, 1990.

GONÇALVES, Amanda Regina. Contribuições da Teoria Histórico-Cultural ao ensino e aprendizagem da Geografia. Estudos Geográficos (UNESP). v. 16, p. 213-224, 2018. Disponível em: https://doi.org/10.5016/estgeo.v16i1.13361. Acesso em: 13 de outubro de 2020.

GONÇALVES, Maria A. S. O método expositivo. Kinesis. v. 13, p. 119-141, 1984. Disponível em:

https://periodicos.ufsm.br/kinesis/article/viewFile/10352/6331. Acesso em: 13 de outubro de 2020.

LARROSA BONDÍA, Jorge. Notas sobre a experiência e o saber de experiência. Trad.: João Wanderley Geraldi. Revista Brasileira de Educação, São Paulo: Anped, n. 19, 2002, p. 20-28. Disponível em: https://doi.org/10.1590/S141324782002000100003. Acesso em: 10 de maio de 2020.

LIBÂNEO, J. C.; FREITAS, R. A. M. da M. A elaboração de planos de ensino (ou de unidades didáticas) conforme a Teoria do Ensino Desenvolvimental. Texto para uso didático na disciplina Didática e Ensino Desenvolvimental, no Programa de Pós-Graduação em Educação. PUC de Goiás, 2009.

MARTINS, Rosa Elisabete Militz W.; TONINI, Ivaine Maria. A importância do estágio supervisionado em Geografia na construção do saber/fazer docente. Revista Geografia, Ensino \& Pesquisa, v. 20, n. 3, p. 98-106, set./dez. 2016. Disponível em: https://doi.org/10.5902/2236499421000. Acesso em: 20 de maio de 2020.

MICOTTI, Maria Cecília de Oliveira. A Elaboração do Plano de Ensino na Educação Pré-Escolar. Educação: Teoria e Prática, v. 2, n. 2, 1994, p. 30. Disponível em:

https://www.periodicos.rc.biblioteca.unesp.br/index.php/educacao/article/view/2 431. Acesso em: outubro de 2020.

NASCIMENTO, Cláudio C. do; MACEDO, Roberto Sidnei. Prefiro ser uma metamorfose ambulante: um elogio ao pensamento pedagógico complexo na formação de professores. Revista da Faced. n. 09, 2005. p. 171-188. Disponível em: http://dx.doi.org/10.9771/2317-1219rf.v10i9.2691. Acesso em: 20 de outubro de 2020. 
NÚÑEZ, Isauro Beltrán. Vygotsky, Leontiev e Galperin: Formação de Conceitos e os Princípios Didáticos. Brasília: Liber Livro, 2009.

PIMENTA, Selma Garrido; LIMA, Maria Socorro Lucena. Estágios supervisionados e o Programa Institucional de Bolsa de Iniciação à Docência: duas faces da mesma moeda?. Revista Brasileira de Educação, Rio de Janeiro, v. 24, 2019. p. 1-20. Disponível em: https://doi.org/10.1590/s141324782019240001. Acesso em: 20 de maio de 2020.

PONTUSCHKA, Nídia Nacib. A formação inicial do professor de Geografia. In: PICONEZ, Stela C. B. et. al. (Coord.). A prática de ensino e o estágio supervisionado. 3 ed.. Campinas: Papirus, 1998. p. 101-124. (Trabalho original publicado em 1991)

RANGEL, Mary. Métodos de ensino para a aprendizagem e a dinamização das aulas. 4 ed. Campinas: Papirus, 2008.

SOUZA, José Gilberto de; JULIASZ, Paula Cristine Strina. Geografia: ensino e formação de professores. Marília: Lutas Anticapital, 2020.

TARDIF, Maurice. Saberes docentes e formação profissional. Petrópolis: Vozes, 2002. 